Revista Iberoamericana, Vol. LXXVII, Núm. 235, Abril-Junio 2011, 473-487

\title{
"EL VÉRTIGO DEL AGUA" \\ EN LA POESÍA DE NANCY MOREJÓN
}

\author{
POR \\ Patricia GonzÁlez Gómez CÁsseres \\ Smith College
}

El agua como divinidad es considerada sagrada y en muchas religiones se le identifica como elemento purificador. "El alma humana se parece al agua” escribió Goethe, y mientras el alma se parece al agua, el espíritu se identifica con el viento o el aire (Burckhardt). Así como el agua simboliza el alma, también se le considera materia prima del cosmos. En los relatos bíblicos sólo existía un mar original (agua) antes de que la tierra fuera creada. También en el Corán hay un versículo que alude a esta idea: "Nosotros hemos creado toda cosa viviente a partir del agua" (Burckhardt). La flor de loto abierta, asiento de las divinidades de la India, también flota en agua. Todo ello nos lleva al agua como substancia primordial de creación. La cultura del agua se enriquece y evoluciona todos los días. En el vasto campo del arte, en símil perfecto con el poder creativo del agua, están los poetas, con su clara visión, los que tienen esta capacidad de recuperar y trascender los poderes mágicos del agua, y Nancy Morejón no es una excepción (Mora y Montero).

Para Nancy Morejón, la influencia mística más importante es la de la religión afrocubana de descendencia yoruba. En la cosmología de esas religiones no existía nada, sólo el dios Olodumare quien creó unas piedras candentes. Al enfriarse éstas y soplarles, surgió el agua. "En aquellas regiones donde el calor había trabajado más, se formaron los océanos, los ríos y los lagos. Y allá nacieron todas las Yemayás y todas las Ochún” (Castellanos y Castellanos 64-65). El agua casi siempre está representada por la madre protectora que toma diferentes nombres. Dentro de la tradición de la Regla de Ocha en Cuba, la orisha madre representante de las aguas es Yemayá, sincretizada con La Virgen de Regla: "Yemayá es la Reina Universal porque es el Agua, la salada y la dulce, la Mar, la Madre de todo lo creado. Ella a todos alimenta pues siendo el mundo tierra y mar, la tierra y cuanto vive en la tierra, gracias a Ella se sustenta. Sin agua, los animales, los hombres y las plantas morirían” (Cabrera 21). Según algunas historias Yemayá es también la madre que da luz a los otros orishas, "del vientre desmesurado de Yemayá surgieron los demás orishas”, dice un pataki o leyenda (Castellanos y Castellanos 54). 
La capacidad creadora de Yemayá se transfiere a la producción de palabras y versos en los poetas. Para Nancy Morejón, mujer de agua, esta incorporación del elemento líquido que fluye y nutre es un acto natural, consecuente y céntrico al mismo tiempo. En la poesía de Morejón aparece el agua como elemento místico, como fuente de creación, como paisaje, como sabia nutriente, como el amor, como líquido protector que nos rodea, y aún más:

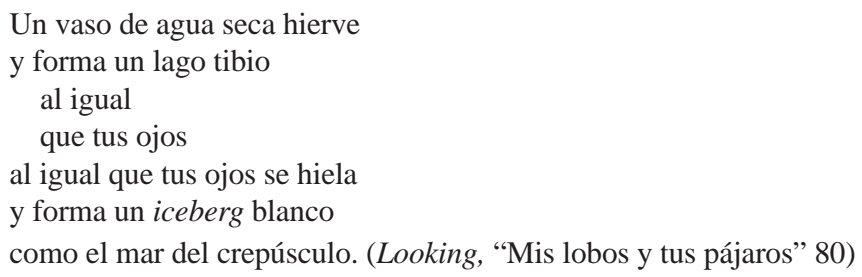

El poema que acabo de citar es un ejemplo donde lo significativo es la aparición del agua de diversas formas: es un vaso de agua, es un lago, podría ser lágrima, es amor y, definitivamente, mar. Morejón, habitante de un terruño rodeado de agua, elabora una poesía empapada de toda esa transparencia acuática. Muchos de sus poemas encierran y/o aluden al agua de una u otra forma, sea directa o por sus atributos. El agua, además de tener el significado de referencia a un paisaje, asume a la vez muchos otros roles y significados en su poesía. Este trabajo pretende ilustrar sólo algunas de esas referencias líquidas en sus versos.

La relación que tiene la poeta con el agua es personal y única, como aparece en el poema "Pudiera". Hay una relación íntima que la conduce a un deseo urgente de comunicarse, de filosofar, de existir a través de la escritura, de confesar, e inclusive, de cuestionar. Es el comienzo del efecto del agua en su proceso creador. Sentir ese líquido en la piel la lleva a la poesía. Sorber la lluvia lleva a la poesía.

o sentir las gotas de agua entre mis manos

súbitamente tengo que hablar

de mis temores a no convertirme en eco (Looking, "Pudiera” 96)

En el poema “Agua” de La Quinta de los Molinos la voz poética nos dice que el agua, de alguna forma, la toca, le hiere, abruma y encanta simultáneamente y aquí el sonido de la lluvia es el que sugiere ese toque mágico.

Me sobrecoge el agua

o quizás el sonido del agua

cayendo de los cielos. (122)

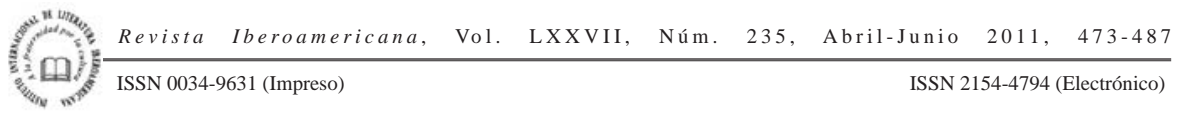


La lluvia se impone, borrando pasados, creando ilusiones, transformando el paisaje. Cito:

La lluvia perdiendo, al fin, su rumbo.

Lluvia perdiendo lluvia

Lluvia cayendo en la memoria

de donde no estamos ni estaremos. (Quinta 52)

La lluvia precursora del antes y el después. La lluvia permanente antes y después del ser, por lo tanto eterna como el agua. La lluvia reconstruye el presente, vuelve a dibujar el porvenir y, en chubascos de borrón y cuenta nueva, hace renacer la esperanza del futuro. La lluvia nos lleva a las olas, a las islas, al mar. Es un solo hilo que fluye y se empalma con las palabras; a veces es tinta que destila palabras; es sonido contra las rocas del camino; la lluvia-agua es también camino. "El vértigo del agua”, de esa corriente transparente, que es tanto lluvia como mar, como río, es más aun, es el sonido del agua y traspasa al mundo en este instante del poema. El agua le permite a Morejón saltar de tiempo, de espacio y cabalgar en el imaginario de la palabra:

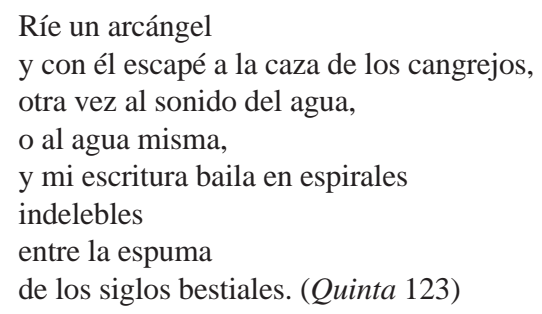

Preñada de agua como vive la poeta, no es de sorprender que esa fascinación por la transparencia líquida sea múltiple. El agua como fuente de inspiración, como fuente de creación, es una de las utilizaciones más importantes y sólidas en su poesía. Un poema que confirma esta idea del agua como elemento motivador que invita a la creación es "Hondo mar" (Quinta 66). Aquí el fondo del mar, con las innumerables opciones de palabras y experiencias existentes en las profundidades, internas o reales como las del mar, inspiran a la poeta. No el agua exactamente sino la inmensidad del océano utilizada como materia prima para la inspiración del artista. El poema comienza así:

Entre la palabra y el silencio

hay un hondo mar, un océano de posibilidades sin fin. [...]

Revista Iberoamericana, Vol. LXXVII, Núm. 235, Abril-Junio 2011, $473-487$
ISSN 2154-4794 (Electrónico) 
Es obvio que para Morejón esa inmensidad azul salina en su vasto horizonte es materia prima de inspiración, pero el reverente momento de enajenación casi mística del proceso creador poético no surge sólo de los efectos del mar sino que también puede producirse por la invocación del agua dulce del río, como en el poema "Hoja de papel" (La Quinta 69). En este poema las aguas corren, como si fuera tal vez el inconsciente del creador, y a cuentagotas llega a empapar el papel de palabras.

Ahí viene el río.

Están corriendo las aguas del río, lentamente.

Vienen las aguas limpias del río atravesando la luz de este papel (69)

Las palabras son los peces que aparecen de pronto entre las piedras o la hierba o es "un pez/ [que] ha iniciado su vuelo silencioso hacia el fondo perenne de esta página” (69). Son peces voladores que corren con las aguas y de vez en cuando se dejan atrapar por las redes de la imaginación. En este poema, el agua es materia prima y el proceso creador es casi como la maestría del pescador para capturar preciosas palabras. Una vez sumergida la palabra en el agua del río, en su corriente, surge un cambio y pasa a ser palabra vidente y los ojos "son el río, para permanecer y volver a bajar hacia el fondo de la pupila".

Un cuarto poema que confirma y refuerza esta idea del agua como elixir sonoro escuchado sólo por los poetas es “Escuchar un estanque” (Quinta 110). El agua promotora de inspiración aquí no es el mar ni el río, sino un estanque que surge como la fuente del proceso, como un rico pozo maleable, oscuro y misterioso.

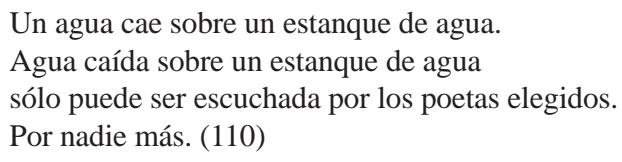

La voz poética busca en la noche las palabras. Le rodea la incertidumbre, el rumbo del verso, el nombre mismo del poema. Se forja ella misma a medida que las palabras surgen como murmullos accidentales. Se desarrollan ideas y preguntas como, por ejemplo, “¿0 será que el estanque con el agua que le corre por dentro tiene una historia inaceptable?”

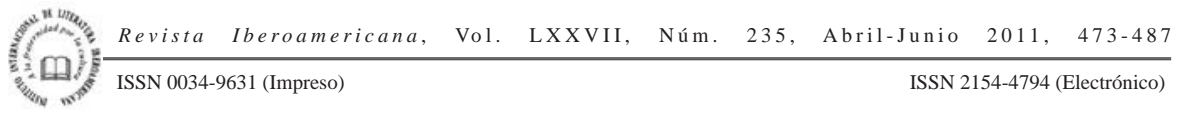


(110) o, “¿por qué escucho ahora con más fuerza que nunca el agua del estanque?” (111) o inclusive la gran pregunta clave, “¿será esto la poesía?” Este poema, más que otros, alude a un proceso creador donde la poeta domestica la palabra. Escucha el llamado que las sirenas le cantaron a Ulises, se encanta, pero su capacidad de forjar el verso en medio del encanto le aterriza en las playas de la poesía. El estanque está habitado, vibra y en sus orillas "hay un dios malva que truena”, así como "una diosa negra bailando” (112); ambos orishas o deidades africanas acompañan a la poeta, junto a este estanque, para que el poema surja. Cito:

Hay un sonido inmenso, monótono, titánico.

Como una campana, la palabra va alzándose

desde los bordes del estanque (Quinta 112)

En el poema “Solaris” (Looking 318) la poeta anuncia que encontró “La creación”, en un lugar donde también halla “comas y naves, módulos y estrellas”, o sea, escritura, mar y espacio. Se tropieza con "la oceánica duna en flor”, junto con el esplendor de los astros, y se confirma una vez más la idea de los poemas anteriores donde la autora identifica el agua como lugar donde reside la inspiración poética, lugar que visitan los creadores y lugar donde se encuentra la poesía misma. Las palabras refuerzan al agua como madre, no sólo como lugar sino también como fuente de la inspiración poética. El final del poema es el siguiente:

Tuve ojos para ver la poesía.

más allá de la muerte y su idea y el tiempo

está el agua científica del lago aquel, corriendo sola y lenta,

temblorosa de frío y de verdad, como una madre. (318)

De nuevo, el "lugar" aparece como mítico, sin tiempo, sin historia, en un espacio húmedo, latente, que gotea elixir, al que solo tienen acceso los poetas, o sea los videntes.

Hay un poema curioso que indirectamente reitera la noción del agua como fuente primaria de la poesía y pone énfasis en la idea del poeta como vehículo que canaliza el melodioso cantar de la poesía. Éste es “Dictado de alcatraz” (Looking 316), y aunque en el poema no se mencione directamente el agua como fuente, sí aparece un ave marina como comunicador de las palabras mágicas que elabora el poema. Aquí se transfiere el poder del agua a un ser del mar que convive y vive de esa agua que le mantiene, por lo tanto, este alcatraz se convierte en el vocero de las palabras que encierran el poder del agua, en su característica de sabia, conocedora del universo. Cito:

Como un murmullo

vuelan las palabras

Revista Iberoamericana, Vol. LXXVII, Núm. 235, Abril-Junio 2011, $473-487$
ISSN 0034-9631 (Impreso) 


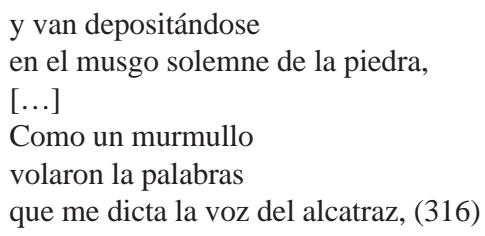

Además de identificar al agua como materia prima de inspiración, en la poesía de Morejón este líquido vital alude también al conocimiento. Parece ser que Morejón utiliza la imagen del agua con el significado de pozo del saber. En estos poemas que veremos, aparece el agua asociada con la sabiduría y se le atribuye a personajes a los cuales la poeta rinde homenaje, como por ejemplo en sus poemas en honor a dos de sus maestras, Mirta Aguirre y Camila Henríquez Ureña. En “Casa emboscada”, poema a la casa de Mirta Aguirre, aparece el agua de nuevo como elemento que abriga y unifica; es un agua mítica que invade la casa. El viajero que pase por aquel hogar se topará "en medio de la sala pequeña,/ [con] una lección aprovechable de sabiduría humana, fija en cualquier página de un libro” (Quinta 100). La casa está descrita como abrigo de aves pasajeras, refugio de mentes inquietas y “dicha necesaria”. Para aquellos privilegiados que entran a la casa, Morejón les invita a navegar ya que la imagen que utiliza para rememorar aquel lugar es el agua. En aquel recinto hay sabiduría, hay agua, y cito:

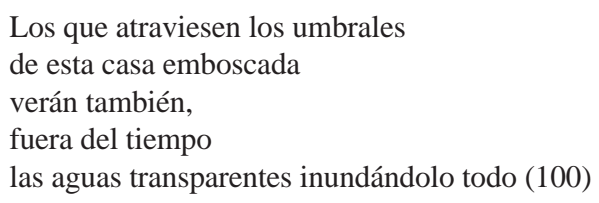

Más evidente aún se hace la analogía en el poema a su profesora universitaria, en donde el homenaje no es a un espacio, sino a un personaje. "Escrito al final del siglo, para una semblanza de Camila Henríquez Ureña” (Quinta 102) es un poema que menciona la personalidad inquieta y carismática de Camila. A ella se acercaban "los Adelantados”, aquellos que buscaban beber en busca del saber, en busca de maestra, en busca de caminos. A todos aquellos pupilos, entre ellos Morejón, Camila los llevó a las aguas de "las literaturas infinitas de la humanidad toda”, y allí los dejó, empapados, picados por sus historias, por aventurar como Odiseo y por conocer más y mejor, como la misma Nancy nos dice:

Camila nos hundió en el valor de conocimiento, en las aguas de Artibonite y en las de la imago Ya nunca más salimos a flote sino que respiramos

Revista Iberoamericana, Vol. LXXVII, Núm. 235, Abril-Junio 2011, $473-487$
ISSN 2154-4794 (Electrónico) 


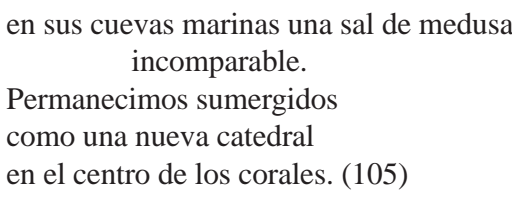

Es evidente que identifica a Camila como marina, y su reino el mar, donde cobija saberes, corales y premios preciados otorgados en esta universidad universal que Morejón cobija, en su visión, bajo el mar.

El agua en Morejón tiene una tercera utilización importante relacionada con la historia del negro en el Caribe; es una relación con su historia, malbaratada oficialmente e inventada y construida en el imaginario colectivo de aquella raza que sufrió la ignominia de la esclavitud. Ya la crítica Juanamaría Cordones-Cook bien nos decía en la introducción de Looking Within que "Mediante su poesía, Morejón busca resistir el fluir del tiempo y el inevitable olvido construyendo memoria para retener, sustantivar y perpetuar lo transitorio y efímero de su mundo y experiencia personal” (30). Pero además de la historia que siempre es personal, está la colectiva, la del grupo, y ellos incluyen a su gente afrocubana. El mar está íntimamente ligado a esa historia de la trata de esclavos africanos porque aquellos galeotes, con su carga infame, lo atravesaron. En "Humus inmemorial", lo reconstruye de la siguiente forma:

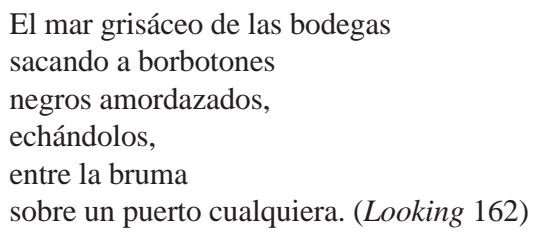

Parte de esa re-construcción de la historia perdida se encuentra también en su conocido poema "Mujer negra" (Looking 200) donde Morejón traspasa los siglos para seguir los pasos de la joven negra desde las costas de África a las cadenas que atraviesan el mar, a la amante del colonizador, a la revolucionaria. Allí surge de nuevo el mar y su travesía como recuerdo ancestral en el imaginario colectivo del pueblo afrocaribeño. Cito:

Todavía huelo la espuma del mar que me hicieron atravesar.

La noche, no puedo recordarla.

Pero no olvido el primer alcatraz que divisé.

Altas, las nubes, como inocentes testigos presenciales.

Acaso no he olvidado ni mi costa perdida ni mi lengua ancestral. (200)

Revista Iberoamericana, Vol. LXXVII, Núm. 235, Abril-Junio 2011, $473-487$
ISSN 0034-9631 (Impreso) 
Un poema en donde también se engloba a la mujer negra a través de su historia de explotación es "La silla dorada”, primer poema de La Quinta de los Molinos. Aquí aparece la propia identificación de la poeta con el agua desde una perspectiva ancestral y también cotidiana. En "La silla dorada", la mujer se encuentra sentada frente al mar y representa de nuevo a la mujer negra reinventada, desde la que llegó sin lengua conocida, a sus abuelas, a sí misma, recicladas todas dejando huellas indelebles en la historia.

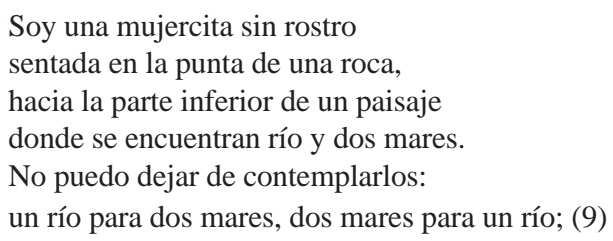

Se identifica la poeta como que viene del agua, orientada hacia el agua, no puede dejar de contemplar el agua, el agua es reflejo de su rostro, el agua une todos los ojos que la contemplaron desde el pasado. Los versos "No sé hablar ni tengo manos./ Un látigo inmemorial las fue cortando poco a poco” (Quinta 9), nos remonta al pasado. El "yo" es la mujer negra esclava, quien "apenas tiene lengua para los buenos días y las buenas noches”. Este poema se enfoca más en la experiencia femenina, por lo tanto aparecen las abuelas como víctimas y los abuelos como “depredadores”. Más tarde el poema enfoca el pasado inmediato del plano personal. Hay una queja honda y profunda, hay un dejo de resentimiento, hay orgullo presente y ancestral, hay un "soy quien soy sobre una silla dorada” a pesar de que su maravillosa piel le imposibilitara estudiar en La Sorbona.

En “Junto al Golfo" (Looking 286), vuelve a insistir la poeta en la partida de África y la llegada al Nuevo Mundo americano como parte de la experiencia compartida y perdida en los anales de la historia. Junto al golfo están las costas. Junto a las costas llegaron los esclavos y cerca de ellas permanecieron, algunos con esperanzas de volver, otros con añoranzas, a reconstruir. Junto al golfo viven los descendientes de los que atravesaron en galeotes. Junto al golfo se identifican, inscriben y escriben. El poema es intrínsecamente acuático desde su título con la mención del golfo hasta su contenido marítimo. El golfo es el de Guinea, el de México, de Honduras, de Tehuantepec. El golfo fue lugar de cimarrones en el continente, fue amargura a la llegada y fue libertad adquirida. Desde el golfo se veían los horizontes perdidos y se elaboraban estrategias de supervivencia. El poema termina en forma positiva con la esperanza de la reconstrucción de una identidad americana en el nuevo suelo adoptado:

Cimarrón en la noche estamos en las aguas

azules y encuentras nuevas islas

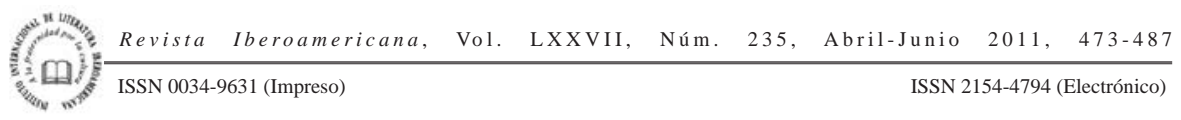


nuevos seres

que nadan junto al mar. (286)

La historia colectiva de su gente no es sólo la historia de la esclavitud y la travesía. También hay otras historias que Morejón cuenta que encierran la vida del mar, de los muelles, de los barcos, de la pesca, y que abarca la historia de los obreros no contada en los libros oficiales, ni en los documentados. En el poema "El hogar" (Looking 220) se recuenta la vida de "un sano estibador", cuyo hogar se adorna con "anémonas, pargos y carnadas”. Son hombres que Morejón denomina "hijos de Yemayá”, la reina de los mares, por eso son "seres del mar" y sus bocas "son saladas". La referencia a la orisha Yemayá es múltiple en la obra de Nancy y complementa las referencias al mar, al agua salada existente en su obra.

La poeta, además de recordar una historia colectiva, recurre a su vez en sus poemas a una historia personal. En "Restos del Coral Island” (Looking 100), ella evoca el recuerdo de su padre cuando le decía: "Esa chatarra que se ve en la orilla/ son los restos del Coral Island". Barco que naufragó en las costas habaneras y cuyos hierros recordaban la historia y la invasión del imperio del norte. La respuesta de la poeta al recuerdo de aquella voz del pasado es la siguiente:

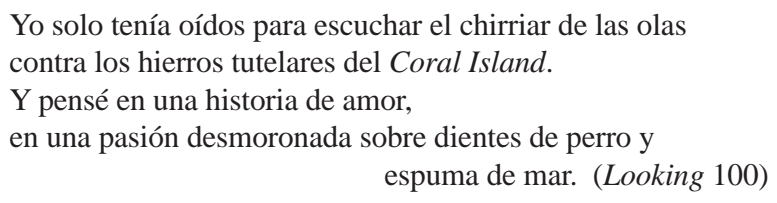

No podemos dejar de mencionar que muchas referencias que aluden a la propia autora se identifican con el mar. En el poema "Renacimiento", por ejemplo, los versos de Morejón manifiestan una identificación personal de la poeta como hija del mar, por lo tanto hija de la orisha Yemayá:

Hija de las aguas marinas, dormida en sus entrañas, renazco de la pólvora (Where the Island 30)

"Pies sobre algas muertas" (Quinta 129) es un poema donde la autora nace literalmente del mar, como la Venus de Botticelli, mantenida y alimentada por las algas, por la vegetación marina. Su energía, expresada a través del baile, proviene del mar mismo. Aunque el poema empieza con pies sobre algas muertas, estas algas se regeneran y llegan a ser vivas y verdes. Hay una aparente simbiosis entre las algas muertas/vivas y los pies que se lanzan a bailar el ritmo de las aguas que le dan vida,

Revista Iberoamericana, Vol. LXXVII, Núm. 235, Abril-Junio 2011, $473-487$
ISSN 2154-4794 (Electrónico) 
alegría y todo un torbellino de creatividad. Es el mar, a través de sus algas, su ritmo, su espuma y oleaje, el que la mantiene llena de vitalidad, escuchando alcatraces que la poeta transcribe a dulces versos.

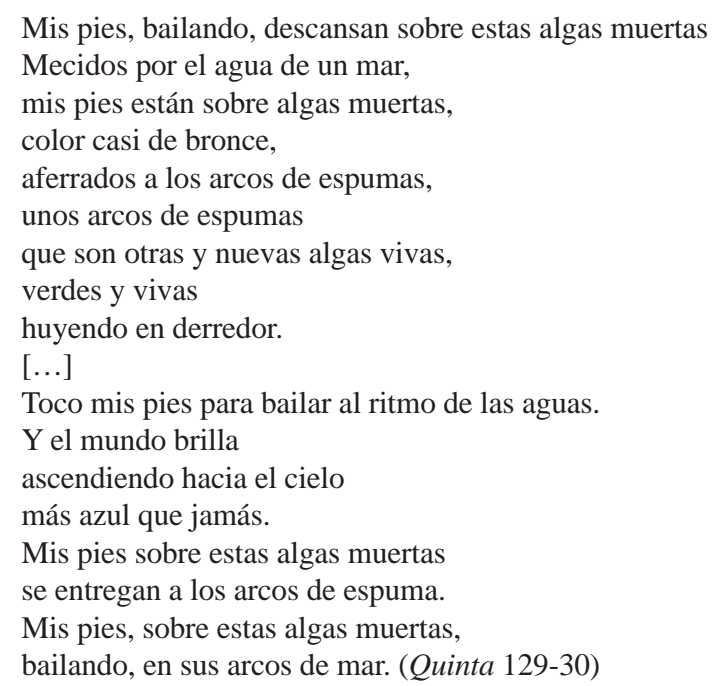

A modo de anotación, un comentario sobre las algas merece mención. Hay muchas algas en los poemas de Morejón. He llegado a la conclusión de que las algas son elemento nutritivo que sostiene, que amamanta, el equivalente a la leche del mar. En un verso sobre un pescado que llevan a la paila dice: "va cabeceando y aleteando y soñando con chorros de algas vivas" (Looking 102), obviamente deseando el sustento que ya no saboreará. En otro poema amoroso menciona que "ingrávida también con mi radar de algas muertas/ alcanzaba el amor" (Looking, "Solaris” 318) lo que comprueba una vez más la capacidad mágica de las algas. En el poema donde establece su casa como barco se mencionan las algas, junto a las tortugas, como algo sagrado: "Oh las tortugas sacras: ay, las algas" (290), y en "Papagayos" surge la frase, "trayendo algas del fondo de los mares" (Looking 268), lo cual nos habla de un alimento profundo, por lo tanto, restaurador.

En el poema "El tambor" (Looking 156) aparece también la asociación de la poeta con el mar. Hay versos como "Mi cuerpo como islas", "Mi cuerpo en el coral”, "Fuego sobre mis aguas", o "Aguas irreversibles en los azules de la tierra”.

Además de la identificación personal con el agua, en el poema "Mundos” (Looking 290) la poeta anuncia: “mi casa es un gran barco". Esto significa que ha escogido el mar como lugar de morada. "Mundos” es un poema puente que unifica el África ancestral

Revista Iberoamericana, Vol. LXXVII, Núm. 235, Abril-Junio 2011, $473-487$
ISSN 0034-9631 (Impreso) 
y el nuevo hogar americano. El mar como lugar de residencia le permite a la poeta navegar por las aguas visitando golfos de ambas costas, navegar entre ambos mundos, escogiendo ser de aquí y de allá simultáneamente sin tener que pisar tierra firme en forma definitiva:

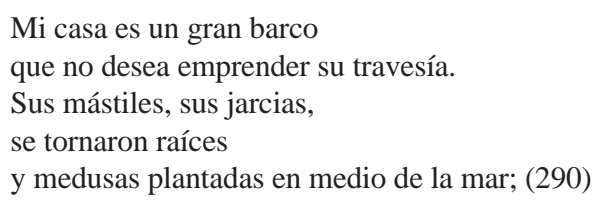

En el poema se ve el mar de nuevo con ojos amargos en recuerdo de las travesías forzadas, pero también se ve como alternativo refugio ante la dicotomía existencial de vivir entre dos mundos separados. La opción del barco hace que el mar se convierta en puente unificador en vez de espacio de separación, o sea que a pesar de versos como "por el oro fétido del galeón desollado" o "los furtivos ojos del pasado mortal", el mar en el poema tiene una connotación positiva, sanadora y de esperanza. Al murmullo de un antepasado esclavo, la voz de "vamos a andar" se convierte en arenga perdonatoria, consciente de un futuro preñado de posibilidades.

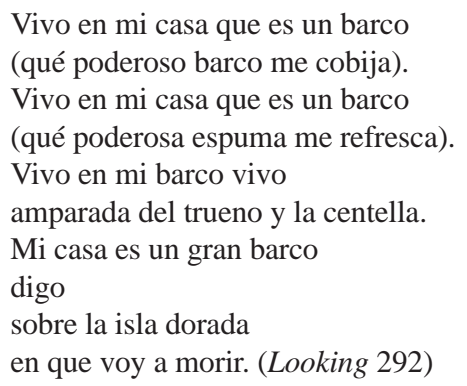

Es importante mencionar además que Morejón utiliza el agua y, de nuevo, el mar y sus atributos para describir el amor. A veces son atributos marinos para las descripciones, a veces aparece el mar como paisaje de fondo a asuntos del corazón, y otras veces se confunde el amor con lo marino mismo. Para ilustrar este aspecto pasional del mar veamos el poema “¿Por que pensar así en tus ojos?” (Quinta 85). Hay un juego con el mar que simula ser el diálogo amoroso con el ser amado. Desde el comienzo del poema se asocia al ser amado con el mar: "Amor mío, tu rostro está junto a la playa./ Sal vi en tus pies”. Más adelante en el poema ya aparece la identificación del amor con el mar: "Vi peces en tus ojos: Una vida marina.// Ven tú, de nuevo con tus filtros de agua, con las ostras y langostinos... ¿Habrá en tus ojos islas inexploradas?” (85). El poema

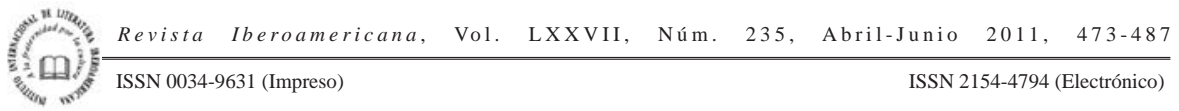


termina anunciando que "la máquina del tiempo termina en el mar" donde encuentra al ser amado en "una válvula de conchas”. Es evidente que la asociación del mar con el deseo amoroso lleva a la poeta a utilizar elementos marinos al evocar la pasión. A veces el mar y sus atributos se utilizan para describir a un personaje, como al muchacho del poema “A un muchacho” (Looking 150). Es otro poema de amor donde la poeta se rinde al personaje en un ambiente marino.

\author{
Entre la espuma y la marea \\ se levanta su espalda \\ cuando la tarde ya \\ iba cayendo sola.
}

Tuve sus ojos negros, como hierbas,

entre las conchas brunas del Pacífico.

Tuve sus labios finos

como una sal hervida en las arenas. (150)

Para concluir con los siguientes versos:

Entre sus brazos, vivo.

Entre sus brazos duros quise morir

como un ave mojada. (150)

De nuevo, elementos como espuma, marea, conchas, sal y arena, todos ellos juntos evocan el mar. El ave mojada, la humedad, y en su conjunto no dejamos de unir la condición amorosa, este joven caminado al atardecer y el mar.

El poema dedicado a la bailarina Nieves Fresneda la identifica desde el primer verso como marina: "Como un pez volador: Nieves Fresneda", (Where the Island, "Elogio a Nieves Fresneda” 68). Nieves fue integrante del Ballet Folclórico Nacional de Cuba y su baile a la orisha Yemayá, la diosa del mar, revolucionó el baile tanto en la isla como fuera de ella. El elogio de Morejón establece una íntima unión entre la bailarina y el mar. Los versos que siguen lo atestiguan:

Olas de mar, galeotes, azules pétalos de algas

cubren sus días y sus horas, renaciendo a sus pies.

[...]

Sus pies marítimos,

al fin,

$\begin{array}{llllll}\text { ISSN 0034-9631 (Impreso) } & \text { ISSN 2154-4794 (Electrónico) }\end{array}$ 


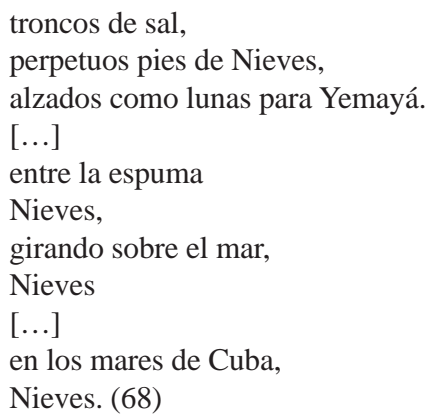

Por último, me gustaría mencionar que Morejón también utiliza el agua palpable que esta allí enfrente del Malecón en sus diferentes manifestaciones temporales como los huracanes y las lluvias tropicales. "En octubre y el aire” (Octubre 25), el poema enlaza la época de los huracanes con la cotidianidad del Caribe, el mes de octubre y el mar; las amenazas, el peligro que los envuelve y los une a todos ante la vecina calamidad ocasionada por el viento roto.

Todas las olas se levantan y crujen sobre el Malecón.

Desprevenidos, los habaneros corren hacia sus casas.

Los automóviles están evadiendo los zarpazos del mar.

El ruido y el vigor de las olas

nos paraliza la vista

con que contemplamos cotidianas.

[...]

Díganme si es posible

zarandear las columnas de espuma

que el mar erige

cuando nos llega octubre silencioso

con su aire mortal (Octubre 26)

En “Mitologías” el poema comienza con el rugido del viento:

Furias del huracán acostumbrado, vientos misteriosos golpeando el arrecife, palos de muerte y de coral

inundaron las bahías de la Isla (Where the Island 34)

Para una poeta que escribe que nunca vio grandes lagos, el agua se convierte en muchos elementos más complejos que simplemente el líquido azul del horizonte. El

Revista Iberoamericana, Vol. LXXVII, Núm. 235, Abril-Junio 2011, $473-487$
ISSN 2154-4794 (Electrónico) 
huracán aparece como fuerza vital que sacude raíces, no sólo de árboles sino ancestrales. Sacude neuronas, inventa paisajes y derrama poesía:

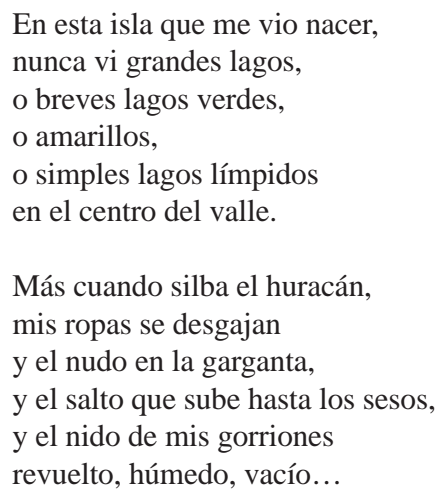

Más cuando silba el huracán, mis ropas se desgajan y el nudo en la garganta, y el salto que sube hasta los sesos, y el nido de mis gorriones revuelto, húmedo, vacío...

(Looking, “Nunca vi grandes lagos” 276)

\section{ConcLusión}

Para Nancy Morejón, como hemos visto, el agua es preciosa, nutritiva, indispensable y poderosa, como debe ser para todos los humanos. La relación que la poeta tiene con este elemento es casi mística y personal. No sólo la baña sino que la ilumina, la motiva, la sacude hasta dejarla tendida enredada con la palabra y el verso. Además de su relación íntima como el agua, la poeta cubana relaciona al agua con la fuente de la inspiración poética y son muchos los poemas que aluden al agua en base a esta función primaria de fuente de la vida y de la poesía. El agua que rodea su isla cumple también con una función histórica porque recuerda la travesía de los galeotes provenientes del África. El agua es cómplice y recordatorio de una historia difícil de olvidar, aunque vaga en documentación oficial. Los poemas de Nancy Morejón se basan en el imaginario colectivo para reconstruir esa historia, y es el agua, en este caso el mar, el que hilvana el proceso de sus ancestros. Vigilando las olas, las pupilas se remontan a un pasado recuperándolo como nuestro, tanto para la poeta como para sus lectores.

Por último, cabe recordar que el agua es vital para Morejón en todo su proceso creador. Su papel ancestral de dar vida se recrea en la poeta en el arte de parir versos. Muchas y diversas manifestaciones líquidas aparecen circulando por las palabras de sus poemas, las cuales, como el agua, continúan empapando al lector de su asombroso poder transformador y de la vitalidad que nos rodea. Reverenciemos, como ella, ese aspecto místico y refrescante del agua al leer los siguientes versos:

Revista Iberoamericana, Vol. LXXVII, Núm. 235, Abril-Junio 2011, $473-487$
ISSN 2154-4794 (Electrónico) 


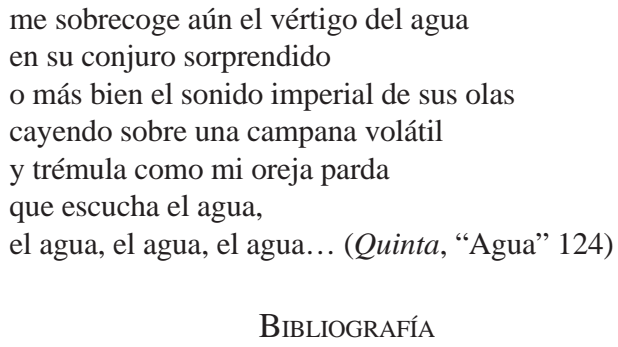

BiBLIOGRAFÍA

Burckhardt, Titus. "El simbolismo ancestral del agua". Espejo del intelecto. Temakel. $<$ http://www.temakel.com/texmitagua.htm>. 18 feb. 2011.

Cabrera, Lydia. Yemayá y Ochún. Miami: Universal, 1996.

Castellanos, Jorge, e Isabel Castellanos. Cultura afrocubana Vol. 3. Las religiones y las lenguas. Miami: Universal, 1992.

Cordones-Cook, Juanamaría. Introducción. Nancy Morejón. Looking Within/Mirar adentro. Selected Poems/Poemas escogidos. 1954-2000. Detroit: Wayne State UP, 2003. 18-36.

Mora, Carlos, y Martha Montero. "Literatura, arte y mitología del agua”. <http://www. imacmexico.org/ev_es.php?ID=22158_201\&ID2=DO_TOPIC $>$.

Morejón, Nancy. Looking Within/Mirar adentro. Selected Poems/Poemas Escogidos, 1954-2000. Juanamaría Cordones-Cook, ed. Detroit: Wayne State UP, 2003.

Octubre imprescindible. La Habana: UNEAC, 1982.

La Quinta de los Molinos. La Habana: Letras Cubanas, 2002.

Where the Island Sleeps Like a Wing. San Francisco: Black Scholar, 1985.

Revista Iberoamericana, Vol. LXXVII, Núm. 235, Abril-Junio 2011, $473-487$
ISSN 0034-9631 (Impreso) 
